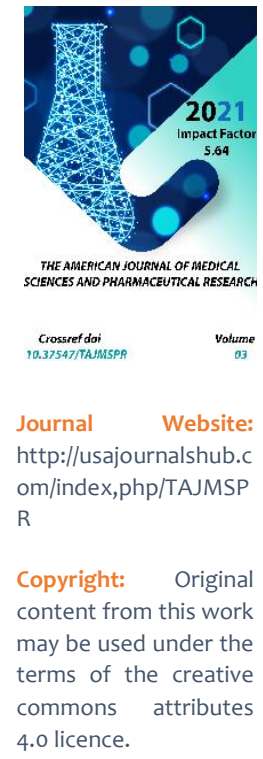

\title{
Clinical Features Of Irritable Intestinal Syndrome
}

Makhmudova L.I.

Bukhara State Medical Institute, Bukhara, Uzbekistan

Shazhanova N.S.

Bukhara State Medical Institute, Bukhara, Uzbekistan

Akhmedova N.Sh.

Bukhara State Medical Institute, Bukhara, Uzbekistan

\section{ABSTRACT}

Irritable bowel syndrome (IBS) is a biopsychosocial disease consisting of a set of functional disorders not explained by organic changes in the intestine. A total of 117 patients and healthy people were examined. Patients were divided into 2 groups: the first group were patients with IBS, which were divided into 2 subgroups: IBSd (diarrhea) - 51 patients ( 20 men and 31 women), IBSc (constipation) - 66 patients ( 33 men and 33 women). More abdominal pain syndrome was noted in patients with a clinical form of IBS with a predominance of diarrhea. The ordinal assessment of the severity of SRC symptoms allows to objectify the severity of clinical manifestation of intestinal dysfunction in patients, identify the clinical features of the course of this pathology.

\section{KEYWORDS}

Irritable bowel syndrome, clinical symptoms, psychological status.

\section{INTRODUCTION}

Irritable bowel syndrome (IBS) is a biopsychosocial disease consisting of a set of functional disorders not explained by organic changes in the intestine (Sheptulin A.A., Vize-
Khripunova MA, 2016, Hanyukov A.A., Fedorova N.S., 2017). 
A meta-analysis published in 2012 found that the prevalence of IBS in the world was $11.2 \%$ when 80 clinical trials were conducted on a total of 260,960 patients, subject to strict selection criteria (Lovell RM, Ford AC., 2012). Only 12-15 percent of patients seek medical attention. IBS incidence is $7 \%$ in Southeast Asia, $20 \%$ in Europe and $21 \%$ in South America. According to the literature, the number of patients with functional disorders of the gastrointestinal tract, including IBS, in specialized gastroenterological hospitals reaches 41-45\% (Pogromov AP, Mnatsakanyan MG, Tashchyan OV, 2016). The incidence of IBS among women remains higher than that of men. Young people are more likely to get the disease than people over the age of 50. Any manifestation of the clinical manifestations of IBS in patients of the older age group should alert the physician to the exclusion of organic pathology.

Analysis of modern data on the etiology and pathogenesis of functional pathology of the digestive tract allows us to comment on the concept of disease formation, obviously, it is not one, but several etiological factors, and in turn these factors are associated with not one but several pathophysiological mechanisms. And the complexity of controlling such patients is that the combination of etiopathogenetic mechanisms in each individual case is individual. Among them are: socioeconomic status, genetic predisposition, the possibility of disease in children of parents with IBS, psychological aspects, hypersensitivity of the internal organs, disorders of the gastrointestinal tract, changes in the neuroendocrine system (brain-intestinal) axis), low-grade- inflammation, the concept of post-infectious IBS, microflora imbalance and, finally, nutritional factors (Maev I.V., Cheremushkin S.V., Yu.A.Kucheryavyy, 2016, Maev I.V., Cheremushkin S.V. et al., 2016).
The purpose of the study. A study of the clinical symptoms of patients with different forms of IBS and assessment of quality of life using a special questionnaire.

\section{MATERIAL AND RESEARCH METHODS}

The study was conducted in the gastroenterology department of BRMMC (Bukhara Regional Multidisciplinary Medical Center) and all patients treated with IBS in an inpatient setting for 2017-2019 were selected. The diagnosis of IBS was made based on IV Roman criteria (2016), using the Bristol fecal forms scale to determine the clinical form of IBS (Blake M.R., Raker J.M., Whelan K., 2016). Determination of the composition of chemical elements was carried out in the laboratory of the Institute of Nuclear Physics of the Academy of Sciences of the Republic of Uzbekistan.

Criteria for inclusion: Conformity of the diagnosis of IBS to the IV Roman criteria, age from 18 to 45 years, a letter of written consent.

Exclusion criteria: patients older than 45 years, "anxiety symptoms" (weight loss; onset of disease in old age; nocturnal symptoms; colon cancer, celiac disease, ulcerative colitis and Crohn's disease among relatives, persistent severe abdominal pain as the only symptom of gastrointestinal tract injury), fever, hepatitis and splenomegaly, anemia, leukocytosis, increased ECG, the presence of occult blood in the stool, changes in the biochemical analysis of blood, steatorrhea and polyphagia).

A total of 117 patients and healthy people were examined. Patients were divided into 2 groups: the first group were patients with IBS, which were divided into 2 subgroups: IBSd (diarrhea) - 51 patients (20 men and 31 women), IBSC (constipation) - 66 patients (33 men and 33 women). The control group included 20 healthy volunteers ( 6 males and 14 females) who underwent prophylactic screening as part of the examination of gastrointestinal tract 
pathology at BRMMC. The mean age of the control group was $25.75 \pm 4.02$ years.

Esophagofibrogastroduodenoscopy in all patients (FUGINON. FUGI FILM EPX-2500, 2014, Japan; FUGI FILM-EG-530PF, 2014, Japan), colonoscopy (FUGI FILM-EG-530FL, 2014, Japan), organ ultrasound examination, stool dissection (Vivid S-60,2014, Norway), micronutrient status testing (mass spectrometry method, perkinelmer inc., Shelton, CT 06484, USA) and a special survey to determine quality of life - GSRS.

\section{RESULTS AND DISCUSSION}

The relationship between disease onset and stress was observed in $65(53.7 \%)$ patients with IBS, 36 (29.7\%) reported symptoms after infection, and $20(16.5 \%)$ reported symptoms after taking antibiotics. appeared against the background of non-compliance with diet, alcohol consumption and exercise. The duration of the disease averaged $4.18 \pm 2.11$ years, ranging from 1 to 15 years (Fig. 1).

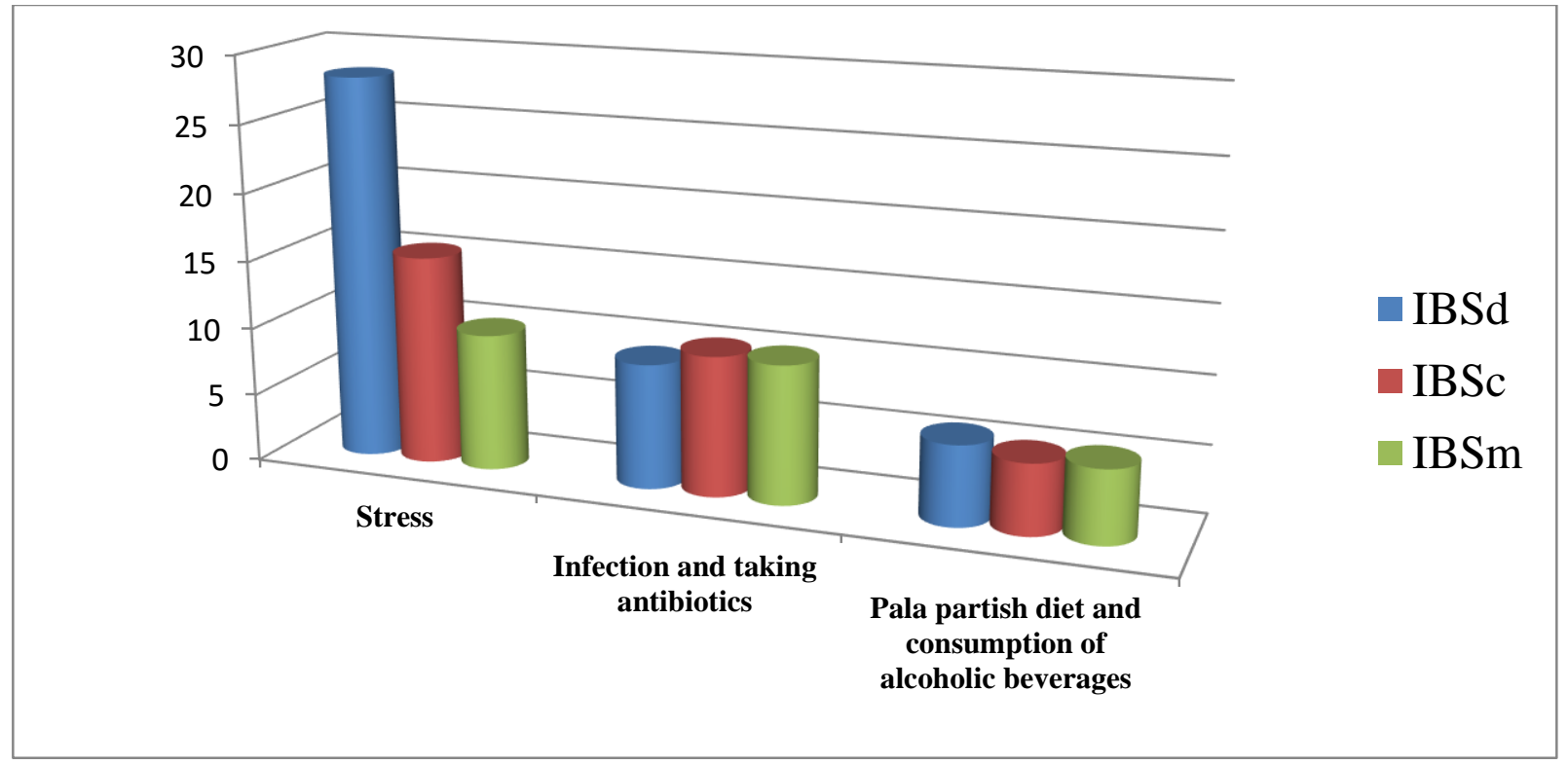

Figure 1. The rate of occurrence of etiological factors in various forms of IBS,\%

For a more correct clinical analysis, we have developed a form-based medical history that took into account the diagnostic criteria of the IBS, as well as the anamnestic, clinical, laboratory peculiarities of the flow pathology in patients. For the convenience of analyzing and subsequent processing, these, we accepted a ballroom system for evaluating symptoms: the lack of a sign was evaluated as o points, from weak severity to moderate manifestations - 1 point, expressed manifestations - 2 points. We summarized the number of points for each patient for three signs (the presence of diarrhea, constipation, pain). Patients who score 5-6 points were attributed to a group with severe / pronounced manifestations that scored 3-4 points - to a group with moderate / mid-severity manifestations, and received 1-2 points - to a group with light manifestations. The criteria for the severity of symptoms are presented in Table 1. 
Table 1

\begin{tabular}{|c|c|c|c|}
\hline $\begin{array}{c}\text { Basic group- } \\
\text { forming symptoms }\end{array}$ & o points & 1 points & 2 points \\
\hline Diarrhea & $\begin{array}{c}<3 \text { times / day 1 time per } \\
\text { week }\end{array}$ & $\begin{array}{c}3-5 \text { times / day 1-2 times a } \\
\text { week }\end{array}$ & $\begin{array}{c}5-6 \text { times / day } 3 \text { times a } \\
\text { week }\end{array}$ \\
\hline Constipation & $\begin{array}{c}<-2 \text { times a week } \\
\text { Pain }\end{array}$ & $\begin{array}{c}1-2 \text { times a week } \\
\text { rarely }\end{array}$ & $\begin{array}{c}>2 \text { times / week + long } \\
\text { strain }\end{array}$ \\
\hline $\begin{array}{c}\text { Flatulence } \\
\text { incomplete emptying } \\
\text { of the intestine }\end{array}$ & + & "Not very serious", often & $\begin{array}{c}\text { Very strong, "terrible" } \\
\text { Feelings of }\end{array}$ \\
\hline
\end{tabular}

The distribution of the patents depending on the severity of the clinical manifestations of the IBS, obtained as a result of the use of a ball assessment of the semptoms of symptoms as follows (table 2).

Table 2

Distribution of patients in the severity of the course of the IBS

\begin{tabular}{|c|c|c|c|}
\hline \multirow{2}{*}{ Group } & \multicolumn{3}{|c|}{ Course of IBS } \\
\cline { 2 - 4 } & heavy & moderate & mild \\
\hline $\begin{array}{c}\text { Group with predominance } \\
\text { of constipation } \mathrm{n}=51\end{array}$ & $8(15,6 \%)$ & $28(54,9 \%)$ & $15(29,5 \%)$ \\
\hline $\begin{array}{c}\text { Group with a } \\
\text { predominance of diarrhea } \\
\mathrm{n}=66\end{array}$ & $18(27,2 \%)$ & $34(51,5 \%)$ & $14(21,3 \%)$ \\
\hline Total $\mathrm{n}=117$ & $26(22,2 \%)$ & $82(70 \%)$ & $29(24,8 \%)$ \\
\hline
\end{tabular}

As can be seen from Table 2, most often, in about half of the patients in each group, with all the clinical manifestations of IBS, the patients had an average severity of the corresponding group-forming symptoms. A point assessment of the severity of symptoms 
in patients with IBS made it possible to identify the clinical features of the course of this pathology, to objectify the severity / severity of clinical signs, to take a differentiated approach to the factors of anamnesis to determine their causal significance and participation in the pathogenesis of this suffering.

The distribution of patients depending on the severity of the manifestations of the IBS in the group with the predominance of the ceiling is presented in table 3.

Table 3.

Severity of signs in patients with IBS with predominance of constipation

\begin{tabular}{|c|c|c|c|}
\hline \multirow{2}{*}{ Sign \patients } & \multicolumn{3}{|c|}{ Course } \\
\cline { 2 - 4 } & heavy & moderate & mild \\
\hline Pain syndrome & $4(7,8 \%)$ & $39,2(46,8 \%)$ & $14(27,4 \%)$ \\
\hline Constipation & $8(15,6 \%)$ & $28(54,9 \%)$ & $15(29,5 \%)$ \\
\hline
\end{tabular}

In order to more objectively, judge the severity / severity of the manifestations of the IBS, we summarized the number of points for each patient on these two features. Patients who scored 5-6 points were attributed by us to a group with severe / pronounced manifestations that scored 3-4 points - in a group with moderate / secondary severity by manifestations, and received 1-2 points - in a group with light manifestations.
A further analysis of clinical data, a clear assessment of some of the initiatives allows you to divide patients with the 2nd group, depending on the severity of IBS symptoms. The distribution of patients depending on the severity of manifestations of the IBS in a group with a predominance of diarrhea is presented in table 4.

Table 4

The severity of signs in patients with IBS with a predominance of diarrhea

\begin{tabular}{|c|c|c|c|}
\hline \multirow{2}{*}{ Sign \ patients } & \multicolumn{3}{|c|}{ Course } \\
\cline { 2 - 4 } & heavy & moderate & mild \\
\hline Pain syndrome & $15(22,7 \%)$ & $31(46,9 \%)$ & $9(13,6 \%)$ \\
\hline Diarrhea & $18(27,2 \%)$ & $34(51,5 \%)$ & $14(21,3 \%)$ \\
\hline
\end{tabular}




\section{CONCLUSION}

1. More abdominal pain syndrome was noted in patients with a clinical form of IBS with a predominance of diarrhea.

2. The ordinal assessment of the severity of SRC symptoms allows to objectify the severity of clinical manifestation of intestinal dysfunction in patients, identify the clinical features of the course of this pathology.

\section{REFERENCES}

1. Sheptulin A.A., Vize-Xripunova M.A. New in the etiology and pathogenesis of irritable bowel syndrome. Klinicheskaya medIBSina. 2016-94-2-92-96.

2. Xanyukov A.A., Fedorova N.S. Possibilities and perspectives in the diagnosis of functional pathology of the intestine. $O$ zdorove rebenka. - Ukraine, 2017-12-2.1-5761.

3. Lovell RM, Ford AC. Global prevalence of and risk factors for irritable bowel syndrome: a meta-analysis. Clin Gastroenterol Hepatol 2012; 10: 712-21.

4. Pogromov A.P., Mnatsakanyan M.G., Tashchyan O.V. The prevalence of irritable bowel syndrome. Klinicheskaya medIBSina. 2016-94-11-869-874.

5. Maev I.V., Cheremushkin S.V., Kucheryavyy Yu.A., Cheremushkina N.V. irritable bowel syndrome. Roman Criteria IV. Consilium Medicum. 2016; 18 (8): 79-85.

6. Maev I.V., Cheremushkin S.V., Kucheryavyy Yu.A. Irritable bowel syndrome. Roman Criteria IV. O role of visceral hyperchuvstvitelnosti i sposobax ee korrektsii. Methodical manual. M., 2016.

7. Baryshnikova N., Belousova L., Petrenko V., Pavlova E. Assess the quality of life of gastroenterologic patients. Vrach. 201362-65.
8. World Gastroenterology Organization global guidelines irritable bowel syndrome: a global perspective / M.M. Eamonn. et al. - 2015. - $30 \mathrm{r}$.

9. Shlyakova A.E., Pantyuxina A.S., Benderskaya E.Yu. Kachestva jizni bolnyx s syndrom razdrajennogo kishechnika $v$ protsesse lecheniya. Health and education in the XXI century. 2017-19-10-143-145.

10. Blake M.R., Raker J.M., Whelan K. Validity and reliability of the Bristol Stool Form Scale in healthy adults and patients with diarrhoea-predominant irritable bowel syndrome. 2016 Oct; 44 (7): 693-703. doi: 10.1111 / apt.13746. Epub 2016 Aug 5. 